\title{
San Juan de Ávila, doctor de la misericordia
}

\author{
Francisco Juan Martínez Rojas \\ Doctor en Historia - Deán Catedral de Jaén
}

\begin{abstract}
Resumen: El Jubileo Extraordinario de la Misericordia ha sido un importante acontecimiento eclesial, que ha permitido profundizar en esta realidad que el Papa Francisco define como "la viga maestra que sostiene la vida de la Iglesia" (Misericordiae vultus 10). En la historia de la Iglesia, los santos han vivido la experiencia de la misericordia de Dios de diversas maneras, y como vivencia personal la han reflejado en sus escritos. Es el caso de San Juan de Ávila, quien trató abundantemente sobre la misericordia tanto en sus obras impresas como en su epistolario y en sus predicaciones. El presente artículo pretende resumir la riqueza del magisterio del Apóstol de Andalucía sobre la misericordia.
\end{abstract}

\begin{abstract}
The Extraordinary Jubilee of Mercy has been an important ecclesial event, which has allowed us to deepen in this reality that Pope Francis defines as "the master beam that sustains the life of the Church" (Misericordiae vultus 10). In the history of the Church, the saints have experienced the mercy of God in different ways, and as a personal experience they have reflected it in their writings. This is the case of San Juan de Ávila, who dealt abundantly with mercy both in his printed works and in his correspondence and preaching. This article aims to summarize the wealth of the teaching of the Apostle of Andalusia on mercy.
\end{abstract}

\section{RECORDAR LA ALTEZA DEL OFICIO SACERDOTAL}

Las primeras palabras que vienen a mi mente en este momento son, lógicamente, palabras de agradecimiento. En primer lugar, quiero expresar mi gratitud al Sr. Arzobispo por haber confiado en mí y permitirme compartir con su presbiterio, el presbiterio hispalense, esta celebración sacerdotal tan hondamente enraizada en la espiritualidad de los presbíteros hispanos, que nos honramos con tener a San Juan de Ávila como nuestro patrón.

Y, como sabéis, no es cualquier patrón el Santo Maestro, el Apóstol de Andalucía, el Doctor de la Iglesia. Es un patrón, un abogado, un intercesor, un 
modelo sacerdotal cargado de futuro, que para nosotros debe ser referencia obligada e imprescindible para vivir nuestro ministerio. No en vano, Benedicto XVI lo definió como un apasionado por la verdad y referente cualificado para la «Nueva Evangelización»1.

En la carta Apostólica Ubicumque et semper, con la que instituyó el Pontificio Consejo para la Nueva Evangelización, el Papa emérito afirmaba: No podemos olvidar que la primera tarea será siempre ser dóciles a la obra gratuita del Espíritu del Resucitado, que acompaña a cuantos son portadores del Evangelio y abre el corazón de quienes escuchan. Para proclamar de modo fecundo la Palabra del Evangelio se requiere ante todo hacer una experiencia profunda de Dios².

Y precisamente ésa ha sido una de las aportaciones más importantes de San Juan de Ávila tenida en cuenta para su declaración como Doctor de la Iglesia universal: la experiencia profunda de Dios, que también nosotros debemos tener como eje vertebrador de toda nuestra vida, para que nuestro ministerio sea fecundo y provechoso en esa ingente tarea a la que toda la Iglesia está llamada, y que denominamos nueva evangelización, o conversión pastoral, como le gusta repetir al Papa Francisco ${ }^{3}$.

Encontrarme esta mañana en el Sagrario de esta Santa Metropolitana y Patriarcal Iglesia Catedral de Sevilla, trae también a mi memoria la presencia aquí, como cura de este templo, del doctor Alonso de Vandelvira, nieto del arquitecto de la catedral de Jaén, a la que tanto tiempo y trabajo dedico. Pero me impresiona más aún, y más vivamente, encontrarme en este lugar celebrando a san Juan de Ávila con el señor Arzobispo, el señor Obispo-auxiliar y los sacerdotes de la archidiócesis de Sevilla, muchos de los cuales también festejan sus aniversarios de ordenación y, todos, su sacerdocio.

Hoy queremos honrar al Santo Maestro, o al Doctor de la misericordia, como he querido titular esta conferencia, quienes somos bien conscientes de"la alteza del oficio sacerdotal". Como si estuviera presente entre nosotros esta mañana, el Santo Maestro vuelve a invitarnos, una vez más, a descubrir la belleza del ministerio sacerdotal, del que el Señor, por pura misericordia, ha querido hacernos partícipes: No es otra cosa más eficaz con que a vuestras mercedes persuada lo que les conviene hacer que con traerles a la memoria la alteza del beneficio que Dios nos ha hecho en llamarnos para la alteza del oficio sacerdotal ${ }^{4}$.

Benedicto XVI, Carta Apostólica declarando a San Juan de Ávila Doctor de la Iglesia, n 1.

<http://w2.vatican.va/content/benedict-xvi/es/apost_letters/documents/hf_ben-xvi_ apl_20100921_ubicumque-et-semper.html>.

3 Francisco, exhortación apostólica Evangelii Gaudium, nn. 25-33.

4 S. Juan de Ávila, Pláticas a los sacerdotes 1, n 1, en San Juan de Ávila, Obras completas [citado en adelante OC], I, Madrid 2000, 786. 


\section{SEVILLA, LUGAR DEL ENCUENTRO DE JUAN DE ÁVILA CON EL DIOS MISERICORDIA}

Hablar de San Juan de Ávila en Sevilla no es un dato secundario o accesorio. No es una circunstancia baladí. Porque fue precisamente en esta ciudad y en su tierra donde tuvo lugar para Juan de Ávila una experiencia que le marcó para toda la vida, que influyó poderosamente en su concepción del ministerio sacerdotal, y se transparentó igualmente en su predicación y en su apostolado.

Me permito repasar de modo muy sucinto algunos datos de la vida de nuestro Patrono. Nacido hacia 1499, en Almodóvar del Campo (Ciudad Real), entre 1520-1526 estudió Artes y Teología en la universidad de Alcalá de Henares, donde la impronta pedagógica que el cardenal Cisneros imprimió a este centro de enseñanza modeló el gusto de Juan de Ávila por la Sagrada Escritura, la teología y la predicación, frente al estudio de los cánones y el derecho civil, que ya había conocido previamente en la universidad de Salamanca.

Ordenado sacerdote en 1526, el que con el tiempo sería llamado Apóstol de Andalucía ya había tomado un camino de desprendimiento y pobreza, que empezando por renunciar a los bienes paternos, hizo que cuando murió no tuviese más patrimonio que una pobre cruz y unos cuantos libros. Si pobre era en hacienda, rico era en deseos de anunciar la Buena Nueva, sobre todo en aquellas tierras que, recién descubiertas allende los mares, necesitaban sembradores de la semilla evangélica.

Con esta idea, para embarcarse hacia América con el dominico Fr. Julián Garcés, nombrado primer obispo de Tlaxcala (México), Juan de Ávila llegó a aquella tumultuosa Sevilla del primer tercio del XVI, paso obligado hacia las Indias.Y aquí encontró a otro sacerdote clave para el s. XVI no sólo hispalense, sino español: el venerable Fernando de Contreras. Fue Contreras el instrumento providencial para cambiar los proyectos de Ávila. Conocedor de las grandes dotes oratorias de Ávila, y de su experiencia en los intrincados caminos del espíritu, dotado como estaba para la dirección espiritual, Contreras instó al arzobispo D. Alonso de Fonseca para que presionara a Juan de Ávila y se quedase así ejerciendo su ministerio en la archidiócesis hispalense. Así lo hizo Fonseca, y de este modo se consiguió que el Santo Maestro no hiciese las Américas y se dedicase al apostolado en Sevilla, mediante la predicación y la dirección espiritual, mientras continuaba los estudios de teología, en los que pudo obtener en el colegio de Santo Tomás el grado de maestro, con el que posteriormente se le conocería: el Maestro Ávila.

El primer sermón lo predicó Juan de Ávila en Sevilla, ante el mismo arzobispo Fonseca, en la iglesia del Salvador, el día de la Magdalena, 22 de julio de 1526. Desde esa fecha -1526- hasta 1533, Sevilla fue el escenario de los trabajos apostólicos del futuro santo, cuya influencia fue más allá de las murallas de esta ciudad, haciéndose presente Ávila en otras localidades, como Écija, Alcalá de Guadaira y Lebrija. 
Su modo de predicar, ardiente y directo, recurriendo constantemente a la Sagrada Escritura, que descendía a cuestiones muy concretas, y no sólo espirituales, sino también muy prácticas y cotidianas, develando en ocasiones vicios y corruptelas muy enquistadas en parte de la sociedad, levantó pronto las naturales suspicacias de quienes no querían ver cuestionado su cómodo cristianismo por una palabra que interpelaba e invitaba a una fe más pura y coherente.

Los detractores de Juan de Ávila recurrieron a una de las vías clásicas entonces para frenar su apostolado, sobre todo su predicación: lo denunciaron calumniosamente al Santo Oficio contra la Herética Pravedad y Apostasía. Ante la Inquisición, Ávila tuvo que declarar, prolongándose su proceso de 1531 a 1533. Pero lo que humanamente es injusticia y pecado en el fondo, Dios lo convierte providencialmente en fuente de gracia.Y así le sucedió a Juan de Ávila en Sevilla. En la cárcel, el futuro Doctor de la Iglesia descubrió y profundizó en el que sería el eje de su rico magisterio. Así lo recuerda Benedicto XVI: En la cárcel comenzó a escribir la primera versión del Audi, filia. Durante estos años recibió la gracia de penetrar con singular profundidad en el misterio del amor de Dios y el gran beneficio hecho a la humanidad por Jesucristo nuestro Redentor. En adelante será éste el eje de su vida espiritual y el tema central de su predicación ${ }^{5}$.

El período que pasó en las mazmorras de la Inquisición, que el licenciado Luis Muñoz, uno de sus biógrafos, califica como duro golpe en un hombre honrado ${ }^{6}$, fue realmente fecundo para San Juan de Ávila. Confiando en la providencia de Dios y en la rectitud de su conducta, o como dice fray Luis de Granada, alegando que estaba muy confiado en Dios y en su inocencia, y que ésta le salvaría el acusado no se dedicó tanto a defenderse frente a sus acusadores -calumniadores más bien-, sino que empleó el tiempo en la oración, en la reflexión y en la Escritura. Durante su encarcelamiento se produjo lo que denomina el cardenal Newman el paso del asentimiento nocional al asentimiento real, es decir, de la aceptación teórica, pero no vivida experiencialmente, de una realidad, a su vivencia real y concreta. Así lo refiere fray Luis de Granada: [como a Jeremías en la cárcel] Pues de esta manera consoló Nuestro Señor a este su siervo estando preso, dándole especial lumbre y conocimiento del misterio de nuestra redención, que es la más alta filosofía de la Religión cristiana ${ }^{8}$.

Es decir, en la cárcel, con lo que implica de experiencia de kénosis, anonadamiento, de abajamiento, de cruz en definitiva, Juan de Ávila captó desde su

Benedicto XVI, Carta Apostólica declarando a San Juan de Ávila Doctor de la Iglesia, nº 2.

$6 \quad$ L. Muñoz, Vida y virtudes del venerable varón el P. Maestro Juan de Ávila, lib. I, cap. 6, en Fr. Luis de Granada-L. Muñoz, Vidas del Padre Maestro Juan de Ávila (ed. L. Sala Balust), Barcelona 1964, p. 174

7 Fr. Luis de Granada,Vida del P. Maestro Juan de Ávila y las partes que ha de tener un predicador del Evangelio, II parte, § 6, en Fr. Luis de Granada-L. Muñoz, Vidas, p. 94.

8 Fr. Luis de Granada,Vida del P. Maestro Juan de Ávila, II parte, § 6, en Fr. Luis de Granada-L. Muñoz, Vidas, p. 95. 
propia experiencia lo que significa que Dios es amor, y que ese amor infinito del Padre se ha manifestado en Jesucristo, que nos ha amado primero, y en la cruz nos ha mostrado que el amor del Padre es, ante todo y sobre todo, misericordia entrañable. Las calumnias vertidas contra él, la privación de libertad, el dolor que esa experiencia negativa provocó en su espíritu hicieron que San Juan de Ávila reviviese, en cierto modo, el proceso injusto de Jesús, o los mismos procesos que debió sufrir el apóstol San Pablo. Pasado el tiempo, Ávila afirmaría: Si vuestras mercedes estuvieran sentenciados a muerte con tres testigos contestes, como yo los tuve, entenderían muy bien a S. Pablo9.

En este período, el Santo Maestro comprendió vitalmente lo que en varios escritos espirituales de la época se denominaba el beneficio de Cristo ${ }^{10}$, un beneficio que no es otra cosa sino la pura gratuidad de Dios en amarnos en su Hijo, amor que, sin embargo, hemos de saber acoger positivamente. Por decirlo con sus propias palabras en el Audi filia, en la cárcel Juan de Ávila puso los ojos en Cristo, y esa perspectiva novedosa cambió su percepción de la realidad, mostrándole la hondura del misterio cristiano:

Poned los ojos en Cristo y pensad con cuánta misericordia se hizo el Hijo de Dios hombre por amor a los hombres, y con cuánto cuidado procuró en toda su vida el bien de ellos y con cuán excesivo amor y dolor ofreció en la cruz su vida por ellos. Y así como, mirándoos a vos, mirasteis a los prójimos con ojos humanos, así mirando a Cristo los miraréis con ojos cristianos; quiero decir con los ojos que Él os mirón ${ }^{11}$.

Se trataría de ver la realidad, por decirlo con los clásicos, no tanto sub specie aeternitatis, sino sub specie Christi, sub specie amoris Dei, o sub specie misericordiae. En adelante, con sus escritos y su verbo ardiente, Juan de Ávila se convirtió en un apóstol, un pregonero del amor de Dios, o lo que es lo mismo, un heraldo de la misericordia de Dios. Repetirá en sus sermones, y dirá una y otra vez en su rico epistolario y en sus restantes obras: Sepan todos que nuestro Dios es amor ${ }^{12}$. O, como afirma igualmente: No penséis, hermano, que tenemos tal Dios que tenga desconsolados a los suyos; que San Pablo le llama Padre de las misericordias y Dios de toda consolación $n^{13}$.

Por todo ello, se puede afirmar que Sevilla fue el lugar del encuentro real y experiencial de Juan de Ávila con el Dios que es amor, que es misericordia, y

9 Declaración del licenciado Bernabé de Ortigosa en el Proceso de Jaén; OC II, Madrid 2001, 12, nota 52.

10 El libro más famoso con este título fue el que escribió Benedetto Fontanini, que fue pronto puesto en el Índice de libros prohibidos y perseguida su difusión por la Inquisición, por contener tesis filoprotestantes:Trattato Utilissimo del Beneficio di Giesu Christo Crocifisso verso $i$ christiani.

11 Audi filia, cap. 95,1: OC I, 742.

12 Sermón 50, 3: OC III, Madrid 2002, 644.

13 Sermón 43, 12: OC III, 572. 
que en su Hijo ha manifestado su amor misericordioso al mundo. Y a partir de ese momento, ése sería el centro de su vida y de sus tareas evangelizadoras. En su ingente trabajo apostólico vemos reflejadas afirmaciones del Papa Francisco en Misericordiae vultus:

Misericordia: es la palabra que revela el misterio de la Santísima Trinidad. Misericordia: es el acto último y supremo con el cual Dios viene a nuestro encuentro. Misericordia: es la ley fundamental que habita en el corazón de cada persona cuando mira con ojos sinceros al hermano que encuentra en el camino de la vida. Misericordia: es la vía que une Dios y el hombre, porque abre el corazón a la esperanza de ser amados no obstante el límite de nuestro pecado ${ }^{14}$.

A San Juan de Ávila se le pude aplicar perfectamente la afirmación del Papa Francisco en la bula de convocatoria del Año Jubilar de la Misericordia, Misericordiae vultus, en cuyo número 10 leemos: La misericordia es la viga maestra que sostiene la vida de la Iglesia. Podemos afirmar, sin establecer un paralelismo forzado u oportunista, que la misericordia es la viga maestra, el leitmotiv, el hilo conductor de la vida del Santo Maestro, de su apostolado, de su obra escrita, en definitiva,la enseñanza sobre la que más escribió y que predicó con más ahínco y pasión ${ }^{15}$. En el subsidio que el Pontificio Consejo para la Promoción de la Nueva Evangelización ha preparado para el Jubileo de la Misericordia, dedicado a los santos en la misericordia, no se ha señalado ni elegido a nuestro santo patrón. Pero méritos no le faltan para poder enumerarlo entre los principales testigos de la misericordia, como bien atestiguan tanto su obra como sus escritos, en los que siempre sale al encuentro del lector o del oyente, a través de la palabra cálida del Santo Maestro, el amor misericordioso de Dios.

Se trata de un amor que Dios derrama misericordiosamente sobre el género humano, pero que reclama una reciprocidad, eso sí, desproporcionada entre criatura y Creador, pero reciprocidad al fin y al cabo. En su Tratado del Amor de Dios, escribe el Santo Maestro: La causa que más mueve el corazón al amor de Dios es considerar profundamente el amor que nos tuvo Él16 ¿Cómo te pagaré, Amado mío, este amor? ${ }^{17}$, ¿Cómo me olvidaré de ti $?^{18}$.

\footnotetext{
14 Misericordiae vultus, $\mathrm{n}^{\circ}$ 2; en <http://w2.vatican.va/content/francesco/es/bulls/documents/papafrancesco_bolla_20150411_misericordiae-vultus.html>.

15 Cf. M. E. González Rodríguez, San Juan de Ávila: de maestro a doctor, en Anuario de Historia de la Iglesia 21 (2012) 23.

16 Tratado del Amor de Dios:OC,I, 951.

17 OC I, 968.

$18 \mathrm{OCI}, 971$.
} 


\section{EL AMOR DE DIOS ES MISERICORDIA}

En el pensamiento de San Juan de Ávila, la vida cristiana tiene un punto de partida inexcusable: la fe en el Dios Amor, que se sustenta y justifica en la bondad y la misericordia divinas, manifestadas plenamente en el misterio pascual de Cristo, y está toda ella movida por el amor a Dios y a los hermanos. El amor hecho misericordia es la clave de todo. En el sermón 76, sobre María Magdalena, predicaba Ávila:

Rezas mucho, pero no amas a Dios, no amas al prójimo, tienes el corazón seco, duro, no partido con misericordia; no lloras con los que lloran; y si esto te falta, bien puedes quebrarte la cabeza rezando y enflaquecerte ayunando; que no puso Dios en eso la santidad, principalmente, sino en el amor ${ }^{19}$.

Como ya ocurriera en San Agustín, Juan de Ávila articula con frecuencia un binomio, cuyos elementos van unidos: miseria - del hombre-, y misericordia -de Dios-.

El reconocimiento de la propia miseria no lleva al desánimo, sino a la confianza en la misericordia divina. Escribe Ávila en el Audi filia: Yasí, Señor, siempre tu gracia y tu misericordia anduvo delante de mí... Porque si tú, Señor, esto no hubieras hecho, todos los pecados del mundo hobiera yo hecho ${ }^{20}$. Se podría hablar un orden de prioridades, en el que el reconocimiento de la propia miseria antecede a la experiencia de la misericordia de Dios: Y si quiere hallar un gran libro para leer cuán bueno es Él, mire cuán malo es vuestra merced, y crea que Dios le ama, y verá un retablo de hermosura de amor pintado en vileza de sus propias maldades ${ }^{21}$.

En sus escritos y sermones, el Santo Maestro sustenta esta visión fundamentalmente en la Sagrada Escritura. La Biblia es el mejor testigo de que Dios es misericordia frente a la continua miseria humana. Así escribe en el Audi filia:

Mas la divina palabra, llena de toda buena esperanza, nos esfuerza diciendo que no desesperemos ni tornemos atrás a los vicios de Egipto, mas que, siguiendo el propósito bueno, con que comenzamos el camino de Dios, estemos en pie confortados con su socorro, para que veamos sus maravillas; las cuales son, que en la mar de su misericordia, y en la sangre bermeja de Jesucristo su Hijo, son ahogados nuestros pecados ${ }^{22}$.

Este texto está tomado del capítulo 21, que, junto con el anterior, el 20, forma como un compendio de la visión que presenta Juan de Ávila sobre la misericordia, apoyada en un nutrido grupo de citas bíblicas.

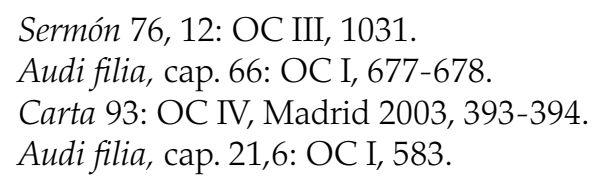


Además de los textos bíblicos, el Santo Maestro sustenta su presentación de la misericordia de Dios también con citas de los Santos Padres (San Agustín, Crisóstomo) y los autores espirituales más clásicos (Juan Casiano, Dionisio Cartujano, San Bernardo, Enrique Herp) ${ }^{23}$.

Pero, podríamos afirmar, Ávila enfatiza más que la mayoría de sus contemporáneos la dimensión misericordiosa del amor de Dios, y la esperanza y confianza que ello genera en el alma cristiana. En el mismo sermón del día de Santa María Magdalena, predicado en Montilla, en 1554, afirmaba el Santo Maestro:

Cosa es que debe alegrar mucho al cristiano oír hablar de Dios y de su condición, para alabar su grandeza, y conocida su condición, agradarle... Maravilloso es Dios en todas sus obras; mas, en lo que toca a ternura de corazón, en lo que toca a entrañas de misericordia, en lo que toca a amar a los hombres, esto es lo que más usa. Porque, aunque todo lo que hay dentro en él, todo es él en los afectos exteriores, lo que más usa es misericordia. Cuando os diere gana de conocer su condición, pensad... que se deleita Dios en amar a los hombres ${ }^{24}$.

Cuando el creyente experimenta la misericordia de Dios, manifestada por Jesucristo y comunicada con la gracia del Espíritu Santo, está anclado firmemente en la esperanza: Y en esta esperanza, y no en la nuestra, hemos de osar emprender la empresa del servicio de Dios ${ }^{25}$. Y en esto estriba nuestra esperanza... en los merecimientos y muerte de Jesucristo ${ }^{26}$.

La esperanza cristiana se apoya en la misericordia de Dios, quien no sólo perdona, sino que da los medios necesarios para salvarse. Los sacramentos, especialmente la Eucaristía, son signos especiales que fundamentan esta confianza ${ }^{27}$ :

¡Qué piadosamente lo hizo el Señor! ¿Cuán gran remedio puso en la sacra comunión contra nuestras desconfianzas! Porque, si nuestro temor nace de que no sabemos si el merecimiento de Jesucristo se aplica a nosotros en particular, no hay cosa tan apropiada contra esta enfermedad como la grande benignidad que en este divino Sacramento se muestra ${ }^{28}$.

Por todo ello, de manera machacona el Santo Maestro invita continuamente a la confianza: ¡Qué prueba nos dio para tener confianza! Desconfiar los hombres de la misericordia de Dios, después de la muerte de Cristo, blasfemias

\footnotetext{
23 En diversas cartas, Ávila cita los libros que sobre todo los predicadores deberían tener, leer o consultar: cartas 1, 5, 8, 225, por ejemplo (OC IV, 12, 36, 38, 51 y 724).

24 OC III, 1027.

25 Audi filia, cap. 27,3: OC I, 596.

26 Sermón 43, 45: OC III, 583.

27 Cf. Audi filia, caps. 18-19, 23-24, 27, 30, 76: OC I, 576-579, 585-590, 595-596, 602-606, 698-701.

28 Sermón 43, 14: OC III, 572.
} 
son grandes ${ }^{29}$. Este hilo conductor de su pensamiento permea, evidentemente, toda la obra literaria de Juan de Ávila. Pero uno de los instrumentos que más usó el santo para invitar a sus dirigidos y conocidos a tener confianza es su rico epistolario. En la vida que escribió de Ávila, afirma fray Luis de Granada que

en estas cartas se señala en alabar la virtud de la confianza en Dios y exhortarnos a tenerla. Esto se verá en sus cartas; las cuales, como por la mayor parte son consolatorias,necesariamente había de aprovecharse de esta virtud para esforzar a los flacos y desmayados con la carga de sus pasiones y pecados, con las sequedades espirituales y ausencias de Nuestro Señor, con las cuales quiere probar la firmeza de su fe y constancia ${ }^{30}$.

Hay epístolas dedicadas totalmente al tema de la confianza, basada siempre en la misericordia de Dios manifestada por medio de Jesucristo crucificado, su Hijo. Se podrían citar las cartas 44, 48, 54, o 90, por citar sólo algunas ${ }^{31}$. En las diversas situaciones a las que da respuesta el Santo Maestro, quiere llevar a su interlocutor un destello de esperanza en la acción de la Providencia, lo que invita a la confianza. Así, invita a tener certeza moral del perdón ${ }^{32}$, gracias a los merecimientos de Cristo, porque, como le escribe a una señora temerosa de comparecer ante Dios, si mira a sí misma, nunca lo merece; si a los merecimientos de Jesucristo, siempre puede llegar con corazón arrepentido y humillado... asiente ya con confianza que el Señor la ama y es con ella ${ }^{33}$. Es como si el predicador, el confesor, el director de conciencias quisiera inculcar en el mayor numero posible de personas esta verdad inexcusable para vivir una auténtica vida cristiana. Escribiendo a un discípulo, cuyo nombre desconocemos, le traza un hermoso plan de vida en el que si bien le recomienda volver sobre sí, mirando cuán indigno es de estar delante de aquel Señor, no se limita a ello, sino que le invita a ir más adelante, pensando los grandes beneficios que le ha hecho

29 Lección 22 sobre 1Jn : OC II, 2001, 439

30 Continúa afirmando fray Luis al respecto: $Y$ aunque par animar a esta virtud haya muchos motivos en las Santas Escrituras, pues, como el Apóstol dice, todas ellas sirven para fundar esta esperanza; pero el principal motivo que para esto hay es el beneficio de la Pasión de Nuestro Redentor, pues nos consta que todo cuanto Él padeció y mereció fue para nosotros, pues Él de nada tenía necesidad. Solos los trabajos y dolores fueron suyos; mas el fruto de ellos todo es nuestro; y con tales prendas seguramente podemos esperar el remedio de nuestros males. Pues de este grande motivo se aprovecha este padre en todas las cartas consolatorias que escribe con tanta fuerza y eficacia de razones para esforzar corazones flacos, que puede él en su manera decir aquellas palabras del Profeta: El Señor me ha dado una lengua sabia y discreta para que sepa yo consolar con mis palabras y los que están caídos y desmayados (Fr. Luis de Granada,Vida del P. Maestro Juan de Ávila, I parte, cap. 3, § 9, en Fr. Luis de Granada-L. Muñoz, Vidas, pp. 69-70).

31 OC IV, 225-233, 243-245, 258-260, 376-387.

32 Carta 160 (A un predicador), contra la tentación de la desconfianza, y de los bienes que tenemos en Cristo; OC IV, 550-551: Buena cosa es sentir nuestra falta y pobreza, mas con condición que sintamos la largueza y riqueza de la misericordia de Dios y glorifiquemos su bondad en nuestra maldad, pues sufre con amor a hijos tan faltos, ruines y miserables. ¿Por qué priva vuestra merced a Dios de esta gloria, de ser ancho en el amor para con sus hijos?

33 Carta 89: OC IV, 375. 
[el Señor] desde que le crió, y le ayuda, con ejemplos concretos a reconocer esos beneficios que Dios, por medio de su Hijo, había otorgado al destinatario de la carta. La conclusión no podía ser otra: Debe procurar el alegría y confianza grande en los merecimientos de Jesucristo ${ }^{34}$.

Fray Luis de Granada, en la ya citada repetidas veces Vida que escribió del Maestro Ávila, afirma que para él una carta, en concreto la 20, era modélica en este aspecto. Fue escrita a una persona de mediano estado, dice fray Luis ${ }^{35}$. En realidad, se trataba de una mujer que sentía mucha ausencia y disfavores de nuestro Señor. No me resisto a consignar algunos párrafos, que sirven de ejemplo representativo de otros muchos textos de nuestro patrón:

No desmayéis, que no os desampararé, aunque os pruebe.Vidrio sois delicado, mas mi mano os tendrá. Vuestra flaqueza hace parecer más fuerte mi fortaleza; de vuestras miserias y pecados saco yo manifestación de mi bondad y de mi misericordia. No hay cosa que os pueda dañar si me amáis y de mí os fiáis. No sintáis de mí humanamente, según vuestro parecer, mas en viva fe con amor; no por las señales de fuera, mas por el Corazón, el cual se abrió en la cruz por vosotros, para que no pongáis duda en ser amados, en cuanto es de mi parte, pues veis tales obras de amor de fuera, y corazón tan herido de vuestro amor de dentro ${ }^{36}$.

\section{LOS SACERDOTES, MISIONEROS DE LA MISERICORDIA}

Este encuentro avilista lo celebramos en el Año Jubilar Extraordinario de la Misericordia. Por ello, quisiera personalizar, en cierto modo, en nosotros todo lo expuesto anteriormente. En nosotros, llamados a ser ministros y misioneros de la misericordia por la ordenación sacerdotal que recibimos. En la bula Misericordiae vultus, el Papa Francisco nos dice: Hay momentos en los que de un modo mucho más intenso estamos llamados a tener la mirada fija en la misericordia para poder ser también nosotros mismos signo eficaz del obrar del Padre ${ }^{37}$.

Se trata de mirar al futuro, y ver cómo se nos plantea una tarea fascinante en los años venideros, años que en el deseo del Papa, deberán estar impregnados de misericordia para poder ir al encuentro de cada persona llevando la bondad y la ternura de Dios A todos, creyentes y lejanos, pueda llegar el bálsamo de la misericordia como signo del Reino de Dios que está ya presente en medio de nosotros ${ }^{38}$.

San Juan de Ávila nos ayuda, con su palabra alentadora e iluminadora, a ser signos eficaces del obrar del Padre, es decir, de la misericordia de Dios, de cara al futuro.

34 Carta 236: OC IV, 752-762 passim.

35 Fr. Luis de Granada,Vida del P. Maestro Juan de Ávila, I parte, cap. 3, § 9, en Fr. Luis de Granada-L. Muñoz, Vidas, p. 70.

36 Carta 20: OC IV, 120-126.

37 Francisco, bula Misericordiae vultus, $\mathrm{n}^{\circ} 3$.

38 Francisco, bula Misericordiae vultus, $\mathrm{n}^{\circ} 3$. 
No podemos olvidar que en su rica doctrina sobre el sacerdocio ministerial, el Santo Maestro parte de una afirmación central, que no es otra sino que el sacerdote actúa in persona Christi. A un discípulo le recuerda en una carta:

Como parece claro en esta su venida; que venía tan manso a darse a todos, y más a los sacerdotes, que tal oficio tenemos y estamos en alto grado, que somos sagrario del Hijo de Dios; que lo que laVirgen soberana trajo en el vientre nueve meses, lo encerramos nosotros cada día en nuestro pecho, y que en la misa nos ponemos en el altar en persona de Cristo a hacer el oficio del mismo Redentor, y hacémonos intercesores entre Dios y los hombres para ofrecer sacrificio; oficio que no tienen los ángeles ${ }^{39}$.

Jesucristo, nos dice el Papa Francisco en Misericordiae vultus, es el rostro de la misericordia del Padre ${ }^{40}$. Si Cristo es la encarnación del amor clemente y misericordioso del Padre, para nosotros sacerdotes, actuar in persona Christi supone de manera inexcusable encarnar el amor de Dios, ser transparencia y testimonio palpable de su misericordia prioritariamente con aquellos que la Iglesia ha puesto a nuestro cuidado, mostrándoles un afecto, un cariño, un amor en definitiva, que San Juan de Ávila, en su Tratado sobre el sacerdocio, define como afecto o amor de padre y madre:

Muchas cosas se requieren para cumplir con la obligación del oficio de cura de almas; porque, si miramos a la dignidad sacerdotal que le es aneja, conviene tener ferviente y eficaz oración, y también santidad, según arriba se ha dicho; lo cual ha de ser con tanta más ventaja en el cura cuanta mayor y más particular obligación tiene de dar buen ejemplo a sus parroquianos y de interceder por ellos ante el divino acatamiento de Dios con afecto de padre y madre para con sus hijos, pues se llama padre de sus parroquianos ${ }^{41}$.

La configuración con Cristo que imprime en nuestra persona la ordenación sacerdotal no es una realidad accesoria o a tiempo parcial. Nos configura tan íntimamente con el único y Buen Pastor, que nuestra vida no puede ser sino como reza el título del famoso libro de Nicolás Cabasilas, una Vida en Cristo. En Juan de Ávila sacerdote se nos presenta una primera característica: la autenticidad, la coherencia, que le llevó a no amar de palabra ni de boca, sino con obras y según la verdad $(1 \mathrm{Jn} 3,18)$. Si, como afirma el Papa Francisco, la credibilidad de la Iglesia pasa a través del camino del amor misericordioso y compasivo ${ }^{42}$, por derivación podríamos afirmar lo mismo de nuestro ministerio: nuestra credibilidad pasa a través del amor misericordioso y compasivo de Dios: experimentarlo en nuestra propia vida y hacerlo experimentar a los demás.

Carta 157: OC IV, 541.

Francisco, bula Misericordiae vultus, $\mathrm{n}^{\circ} 1$.

Tratado del Sacerdocio, 36: OC I, 939.

42 Francisco, bula Misericordiae vultus, $\mathrm{n}^{\circ} 10$. 
En San Juan de Ávila contemplamos un ejercicio del ministerio creíble. Él nunca ejerció el pastoreo por la fuerza, sino con la autoridad moral que se impone por sí misma. Fue el presbítero que nunca olvidó que era ministro de Cristo siervo, esclavo, que no ha venido a ser servido sino a servir hasta dar la vida en rescate por todos. Juan de Ávila ejercía un magisterio fecundo, in vinculis charitatis, nunca como controlador exigente de sus dirigidos, tan en boga entonces y siempre, y lo que otro contemporáneo, San Juan de la Cruz, criticaría tanto. Decía de esta faceta de Ávila fray Luis de Granada:

Pues siendo este cebo de amor un medio tan eficaz para cazar las ánimas, no era razón que a este nuestro cazador, y tan solícito imitador del Apóstol, faltase ese mismo cebo. Y lo que de esto puedo, en suma, decir es que no sabré determinar con qué ganó más ánimas para Cristo, si con las palabras de su doctrina o con la grandeza de su caridad y amor, acompañado de buenas obras, que a todos mostraba. Porque así los amaba y así se acomodaba a las necesidades de todos, como si fuera padre de todos, haciéndose, como dice el apóstol, todo a todos para ayudar a todos. Consolaba a los tristes, esforzaba a los flacos, animaba a los fuertes, socorría a los tentados, enseñaba a los ignorantes, despertaba los perezosos, procuraba levantar a los caídos, mas nunca con palabras ásperas, sino amorosas, no con ira, sino con espíritu de mansedumbre ${ }^{43}$.

Aunque se refería a San Pablo, el Santo Maestro bien podría afirmar de sí mismo: Debía tener entendido el Apóstol que haberle hecho Dios pastor de su Iglesia no había sido hacerle señor, sino padre y madre de todos ${ }^{44}$.

Ese ser el sacerdote padre y madre de todos, por decirlo con las palabras del Santo Maestro, es en definitiva, para nosotros, convertirnos en samaritanos de los hombres y mujeres que nos encontramos en nuestros caminos. Sabemos que en la parábola del buen samaritano el protagonista no es el hombre herido, apaleado por los bandidos, sino quien lo auxilia. Y no podemos olvidar que Jesús narra esa parábola ante la pregunta de un escriba que le pide explicación sobre quién es su prójimo. La respuesta es clara: el prójimo es el que demuestra misericordia.Y así, todos debemos ser prójimos. La parábola es una explicación visual del mandamiento del amor que Cristo ha dejado como distintivo a los suyos. Y si nuestro ministerio es, como decía San Agustín, amoris officium, en nuestra vida se debe transparente nuestra proximidad.

Ser prójimos de los miembros del pueblo de Dios es equivalente a ser misericordiosos con ellos. James F. Keenan, un jesuita norteamericano especialista en moral, dice que ser ministro de la misericordia equivale a entrar en el caos de otras personas $^{45}$. Pero ese acercamiento o aproximación no la podemos realizar si antes

43 Fr. Luis de Granada, Vida del P. Maestro Juan de Ávila, I parte, cap. 2, § 4, en Fr. Luis de Granada-L. Muñoz, Vidas, p. 41.

44 Comentario a los Gálatas, cap. 4: OC II, 81.

45 Cf. su obra Le Opere di misericordia cuore del cristianesimo, Bologna 2010, passim. 
no entramos en nuestro propio caos, es decir, si desde una actitud de auténtica humildad, que se deriva del conocimiento de uno mismo, de sus límites y zonas oscuras, no asumimos nuestros propios límites y somos conscientes de ellos.

Se trata de progresar en nuestra vida sacerdotal con autenticidad, porque, como escribía Ávila, rigiéndoos bien a vosotros, regís al pueblo ${ }^{46}$. En ese proceso de autenticidad, la pobreza ocupa un lugar importante. Pobreza o austeridad como sacerdotes seculares que no hemos hecho, como los religiosos, voto de pobreza. Ello con el fin de hacer más eficaz el Evangelio que predicamos. Pobreza real, que comienza por el propio conocimiento: conocerse a sí mismo no como una conquista psicológica, sino como modo de encontrar a Cristo en las propias limitaciones: Los que no se conocen por pobres, despídanse de las nuevas que trae Jesucristo pobre ${ }^{47}$. Experimentar nuestra pobreza y limitación, ser conscientes de nuestro pecado no para desanimarnos en una carrera hacia la perfección, que puede estar teñida de autoconquista pelagiana, sino como modo de palpar y dejarnos renovar por una misericordia que luego debemos hacer sentir a los demás. Como escribía a una escrupulosa, el Doctor de la Misericordia también nos dice: Lo que escarbáis en vuestra miseria, escarbadlo en su misericordia, y sacaréis de ello más provecho que de lo primero ${ }^{48}$.

Aquí podemos enlazar con el sacramento de la reconciliación, donde nuestra miseria se encuentra cara a cara con la misericordia de Dios. Como sabéis, el Papa Francisco insiste en que el Año Jubilar de la Misericordia es un momento privilegiado para experimentar el amor de Dios en el sacramento de la confesión. En Misericordiae vultus afirma:

Ponemos convencidos en el centro el sacramento de la Reconciliación, porque nos permite experimentar en carne propia la grandeza de la misericordia. Será para cada penitente fuente de verdadera paz interior. Nunca me cansaré de insistir en que los confesores sean un verdadero signo de la misericordia del Padre. Ser confesores no se improvisa. Se llega a serlo cuando, ante todo, nos hacemos nosotros penitentes en busca de perdón. Nunca olvidemos que ser confesores significa participar de la misma misión de Jesús y ser signo concreto de la continuidad de un amor divino que perdona y que salva ${ }^{49}$.

Parecido énfasis ponía San Juan de Ávila en el sacramento de la reconciliación, cuya importancia ponderaba con mucha frecuencia, sobre todo en los sermones y en los tratados de reforma. En ocasiones se lamentaba que este sacramento no fuese apreciado en toda su riqueza: ¡Cuán mal te sabemos agradecer el poder que has dado a los sacerdotes y cómo los has hecho despenseros de

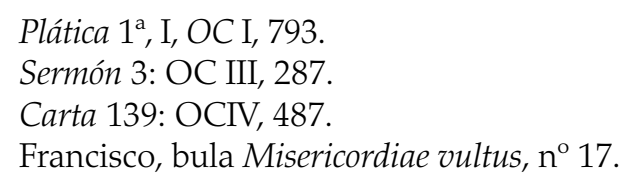


tus merecimientos! ${ }^{10}$ El Santo Maestro invita a los fieles a descubrir la riqueza de la misericordia que se dispensa en la confesión. En el sermón 58 predicaba así: La confesión es para hacer las amistades entre Dios y ti. Estaba Dios airado contra ti, estaban dadas tantas sentencias de muerte para los infiernos contra ti. ¿Te confesaste? Ya eres amigo de Dios; no están ya a tu cuenta aquellos pecados ${ }^{51}$.

Para hacer una buena confesión hay que hacer un buen examen de conciencia. Pues bien, San Juan de Ávila une examen de conciencia y oración: Los pies con que nuestra alma se menea son el examen y la oración. Con los primeros se va al conocimiento propio; con el segundo, al amor de Dios ${ }^{52}$.

Conviene recordar el rico magisterio de San Juan de Ávila sobre la oración. Es tan profundo y amplio, que sólo puedo limitarme a recordar algunos de sus pensamientos, como cuando afirma en el Audi filia: Los que no se cuidan de tener oración, con una sola mano nadan, con una sola mano pelean, con un solo pie andan ${ }^{53}$. Enfatiza el Santo Maestro lo que acabo de señalar: la necesidad de ser hombres contemplativos, orantes, para que nuestras tareas apostólicas sean provechosas para el pueblo de Dios. Así afirma: Pues tiene oficio de orar, tenga vida de oración ${ }^{54}, \mathrm{y}$ más explícitamente advierte: Sacerdote que no ora, darme ha por consejo de Dios consejo suyo ${ }^{55}$. En su sermón su tono es más directo aún para afirmar sin ambages: $\mathrm{Si}$ tuvierais callos en las rodillas de rezar y orar, si importunaseis mucho a Nuestro Señor y esperaseis de Él que os dijese la verdad, otro gallo os cantaría. ¿Quieres que te dé su luz y te enseñe? Ten oración, pide, que darte ha. Todos los engaños vienen de no orar ${ }^{56}$.

Y quisiera terminar finalmente con una referencia mariana. El Papa Francisco afirma en la bula Misericordiae vultus: El pensamiento se dirige ahora a la Madre de la Misericordia. La dulzura de su mirada nos acompañe en este Año Santo, para que todos podamos redescubrir la alegría de la ternura de Dios ${ }^{57}$.

María nos recuerda constantemente la gran misericordia realizada por Jesucristo: recuperar cada uno de nosotros la dignidad de ser hijos de Dios, y ministros de Cristo, servidores del pueblo de Dios. Como afirmaba san Juan Pablo II: Ella es pues la que conoce más a fondo el misterio de la misericordia divina. Sabe su precio y sabe cuán alto es. En este sentido la llamamos también Madre de la misericordia ${ }^{58}$.

Quisiera terminar con una oración del Santo Maestro, Doctor de la Misericordia, que en el sermón 60, pronunciado en la Natividad de María, San Juan de Ávila dirigió a la Virgen, y que os invito a hacer nuestra, en este día sacerdotal:

Sermón 58, 6: OC III, 783.

Sermón 58, 6: OC III, 783.

Carta 232: OC IV, 739.

Audi filia, cap. 70: OC I, 688

Audi filia, cap. 76: OC I, 699.

Sermón 5: OCIII, 95.

Sermón 13: OC III, 192.

Francisco, bula Misericordiae vultus, $\mathrm{n}^{\mathrm{o}} 24$.

58 S. Juan Pablo II, encíclica Dives in misericordia, nº 9; en http://w2.vatican.va/content/john-paulii/es/encyclicals/documents/hf_jp-ii_enc_30111980_dives-in-misericordia.html. 
¡Oh Niña para siempre bendita, la más cercana a Dios humanado de cuantas hay en el cielo y en la tierra!... Vos sois puesta para medio de nuestro remedio delante del acatamiento de Dios; en vuestras manos, Señora, ponemos nuestras heridas para que las curéis, pues sois enfermera del hospital de la misericordia de Dios... Creemos que os dotó Dios de tanta misericordia, que vuestra limpieza y pureza no se desdeña ni alanza de sí a los pecadores llagados, mas que cuanto es mayor su necesidad, tanto más vuestra misericordia os mueve a su remedio...

A vos, Señora, presentamos nuestros males para que delante del trono de Dios los deshagáis y alcancéis perdón de ellos. A vos también presentamos nuestras obras, aunque llenas de muchos defectos, y en vuestras manos ponemos nuestro corazón... para que teniendoos a vos por defensora contra nuestros males y por nuestra en nuestros bienes, los reciba el Señor. Alcánzanos, Virgen Santísima, gracia para que... merezcamos veros en la gloria ${ }^{59}$.

\section{A MODO DE CONCLUSIÓN}

Cuentan fray los biógrafos de Sta. Teresa, que, estando en Toledo, le llegó la noticia de la muerte del padre Maestro Ávila. Su reacción fue echarse a llorar con grande sentimiento y fatiga. Sus acompañantes, que sabían que no había llorado cuando murió su hermano, le dijeron que no se afligiera, porque se habría ido a gozar de Dios. A lo que la Santa respondió: De eso estoy yo muy cierta, mas lo que me da pena es que pierde la Iglesia de Dios una gran columna, y muchas almas un gran amparo, que tenían en él, que la mía, aun con estar tan lejos, le tenía por esta causa obligación ${ }^{60}$. El tránsito le llegó a Juan de Ávila un 10 de mayo de 1569, y nosotros, hoy, nos reunimos en la Eucaristía, de la que tan devoto fue él, para venerar su memoria y dar gracias a Dios por el fecundo magisterio del que con razón fue llamado ya en su tiempo el Maestro.

Lo mismo que quienes vieron las desconsoladas lágrimas de Sta. Teresa, podemos preguntarnos nosotros quién es, quién fue, qué significó aquel sacerdote secular, manchego de nacimiento, andaluz de adopción, universal por su doctrina. Qué tenía la palabra de aquel que juzgaron sus contemporáneos un Pablo redivivo, para que fray Luis de Granada repitiera al pie de la letra gran parte de sus sermones. Qué signos de vida sobrenatural ofrece este santo tan tardío, que vio cómo sus discípulos y dirigidos (Sta. Teresa entre ellos), se le adelantaran vertiginosamente en el camino de los altares, mientras él casi todavía podría estar esperando. Quién fue este Juan de Ávila, que, mientras muchos veían el sacerdocio como una buena carrera, él dejó a un lado honores, prebendas -como la canonjía magistral de la catedral de Jaén-, prelacías -el obispado de Segovia, el arzobispado de Granada-, para retirarse a Montilla y morir sobre un pobre jergón, legando como únicos bienes una pobre cruz de palo, unos cuantos libros

Sermón 60, 32: OC III, 815.

60 Fr. Diego de Yepes, Vida, virtudes y milagros de la bienaventurada virgen Teresa de Jesús, lib. III, cap. 25. 
y un riquísimo magisterio en el que la palabra y el testimonio se unen en perfecta y armoniosa coherencia de vida. Qué atracción tenía este descendiente de judíos, converso, con lo que eso significaba entonces, para cautivar la voluntad de la gran nobleza de Andalucía, de los cristianos viejos de antaño. ¿Cuál es el misterio que encierra la vida de Juan de Ávila? Ese misterio tiene un nombre y un rostro concreto: Jesucristo.

El mismo misterio en el que nosotros, sacerdotes del s. XXI, estamos llamados a profundizar y vivir para ser fieles al ministerio recibido. 